\title{
Analysis of Three Phases Asynchronous Slip Ring Motor Performance Feedback Type 243
}

\author{
Sardono Sarwito ${ }^{1}$, Semin $^{2}$, Achmad Suherman ${ }^{3}$
}

\begin{abstract}
Alternating Current Electric Motor (AC), this motor most widely used. There are two types of rotor on three-phasess asynchronous motor, the squirrel-cage rotor and the slip ring rotor. Every motor has its own characteristic, it have been affect the used of the motor. In this research is aiming to know three-phasess asynchronous slip ring motor performance on unloaded and loaded condition. On its condition, the variation resistance starting from $0 \Omega$ -

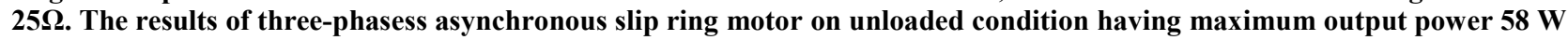
and maximum torque $0.22 \mathrm{Nm}$ in $25 \Omega$ of resistance. While in the condition loaded having a maximum $P_{\text {in }} 131,5 \mathrm{~W}$, maximum $P_{\text {out }} 109,31 \mathrm{~W}$, maximum torque $2,08 \mathrm{Nm}$ and maximum efficiency $95 \%$. The analysis was done by knowing the relation between torque vs speed and efficiency vs load. The result shows that the increasing of motor speed have been give affect the decreasing of motor torque in according with the torque formula. In the other result, it can be seen that increasing of the load, efficiency have been increase.
\end{abstract}

Keywords -asynchronous motor, motor load, performance, slip ring, three phases.

\section{INTRODUCTION}

$\mathrm{T}_{1}$ he asynchronous motor is the most widely used electric current $(\mathrm{AC})$ motor. The naming is derived from the fact that it operates on the basis of the induction of the stator magnetic field to its stator, in which the rotor current of the motor is not obtained from a particular source, but is the induced current as a result of the relative difference between the rotation of the rotor and the resulting rotating magnetic field by the stator current. Induction motors are widely used in everyday life both in industry and at home. This is because induction motor has many advantages compared to other electric motor, that is because of its relatively cheap price, simple and strong construction and good work characteristic.

Three-phases asynchronous motors are the most widely used motor types in the industry, these are the motors that have been be used to rotate the existing load in the industry. Three-phases induction motor having high efficiency usually has small rotor resistance. As a result this motor have been produce a small initial torque and attract a large initial flow. However, sometimes the damaged bar on the rotor shell can cause unbalanced motor windings, which affect the torque and rotation. The motor with the cage rotor is called the induction motor of the cage rotor whereas the induced rotor induction motor is known as the induction motor slip ring. In this asynchronous slip ring motors have been be experimented on the relationship between the loading with the motor efficiency and the characteristics of torque to the rotation produced by the three-phases asynchronous slip ring motors in loaded conditions are

Sardono Sarwito, Department of Marine Engineering, Institut Teknologi Sepuluh Nopember, Surabaya 60111, Indonesia, Email: sardonosarwito@gmail.com

Semin, Department of Marine Engineering, Institut Teknologi Sepuluh Nopember, Surabaya 60111, Indonesia, Email: seminits@gmail.com

Achmad Suherman, Department of Marine Engineering, Institut Teknologi Sepuluh Nopember, Surabaya 60111, Indonesia, Email: achmadsuherman48@gmail.com also reviewed and the asynchronous 3 rotor motor rotation in the ship world.

In the Marine Electrical and Automation Laboratory The Department of Marine Engineering Institut Teknologi Sepuluh Nopember Surabaya, there is a threephases asynchronous slip ring motor from a British feedback manufacturer that has not been used for a long time. Considering that, it is necessary to know the performance of the feedback motor through the method of data collection practice that hope the performance analysis of the three-phases asynchronous slip ring motor can be used as the target of the selection of three-phases asynchronous motor type most efficient in certain usage [1-6].

\section{METHOD}

\section{A. Three-phases asynchronous slip ring motor}

The slip ring motor are different from the squirrel-cage motors in terms of rotor construction. As the name implies, the rotor is wrapped with an isolated winding similar to the stator winding. The rotation of the rotor phase is connected $\mathrm{Y}$ and each open-ended phase is ejected to the slip ring attached to the rotor shaft. Schematically can be seen in the figure 1 .

From the Figure 1, it can be seen that the slip ring and the brush are simply connecting the external variable control resistance into the rotor circuit. In this motor, the slip ring is connected to an external variable resistance which serves to limit the starting current and which is responsible for the rotor heating [7-11].

During starting, the addition of external resistance to the wound rotor circuit produces a starting torque greater than the starting stream which is smaller than the squirrel-cage rotor motor. Construction of three-phases asynchronous slip ring motor is shown in the Figure 2. 


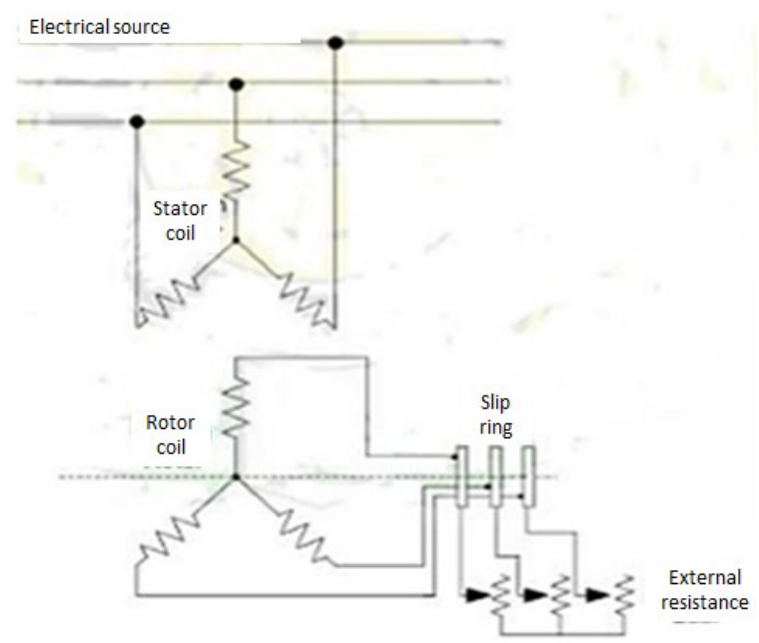

Figure. 1. Schematic diagram of asynchronous slip ring motor

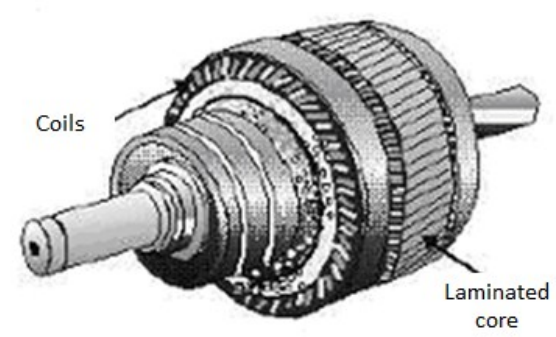

Figure. 2. Wound rotor

- The advantages of asynchronous motor:

High start torque with low start current.

$>$ Acceleration with soft weight.

$>$ No abnormal heating during the starting period.

$>$ Good speed adjustment during working with constant load.

$>$ Speed can be adjusted

- The disadvantages of asynchronous motor:

$>$ Maintenance and initial price is higher compared to squirrel cage motor.

$>$ Speed regulation is bad, when working with resistances on a series of rotors.

\section{B. The starting slip ring motor}

Slip ring motor in the picture below or often called motor rotor induction motor including slip ring threephases motors with rotor turns and comes with slip ring associated with charcoal brush to the terminal. Slip ring motor designed for great power.

Slip ring motor on the terminal box has nine terminals, six terminals connected with three stator entanglement each end (U1-U2, V1-V2 and W1-W2), three terminals (K-L-M) is connected to the rotor through the entanglement slip ring. There are three so-called slip ring connected with the charcoal brush. This charcoal brush must be replaced periodically as it have been shorten because it is worn out.

Starting slip ring rotor in the Figure 3 the terminal ends of the rotor turns the K-L-M associated with the resistor out the magnitude can be arranged. By adjusting the resistor outside means regulating the magnitude of the total is the number of resistors the resistance of the rotor and external resistance $\left(\mathrm{R}_{\text {rotor }}+\mathrm{R}_{\text {outer }}\right)$, so that the rotor currents are $I_{2}$ can be arranged [2].

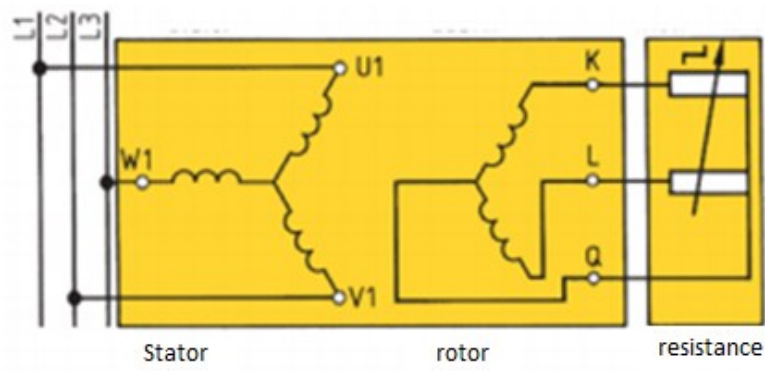

Figure. 3. Motor stator and slip ring rotor resistors on the following series.

When the resistor is valuable, current, maximum rotor minimum flows, as well as improve the working factor of the motor. Starting slip ring rotor advantages such as obtained a high starting torque, starting with a current that remains under control. 
C. Technical features SRM (Slip Ring Motor) and SCM (Squirrel Cage Motor)

The Figure 4 shows that SRM can perform a lot more torque (torque 2.5 torque) than on the SCM (1.6 torque torque) on the initial speed of close to zero and increments the torque down as speed reaches the speed of the identifier by using the conventional control methods.

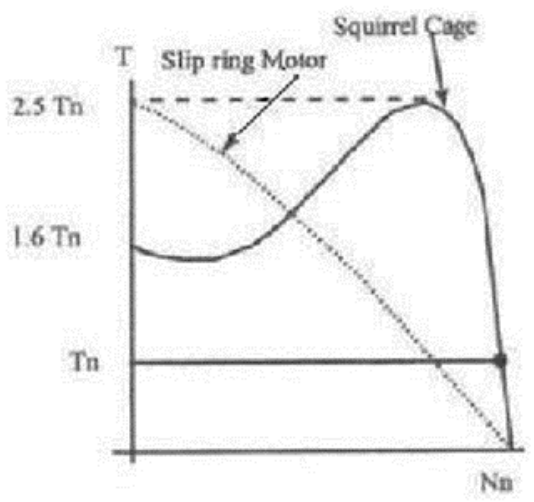

Figure. 4. Torque vs speed SRM and SCM

The methodology in the research is the frame of thinking that is used during the research since the end of the first task is done until the research is completed. Research methodology is needed for the research process to run in accordance with the desired, so as to obtain maximum results. More precisely this research methodology is used to solve previously systematized problems and is expected to achieve the best possible results.

In order to be a test circuit that can produce good data then required a test equipment such as three-phases asynchronous slip ring motor, Three-phases starter motor, single and three-phases measurements, Threephases supply control, cable, variable resistance, variable output voltage, tachometer, digital multimeter, megger tester, digital multimeter.

After that, the testing phase have been be done assembly process equipment that have been proceed with the steps according to the experimental procedures used in the testing process. Here are some series of experiments in the assembly process of equipment. The required data are searched by measuring some parameters required according to the observed variables to perform the calculations and analyzing the performance of the motor if loaded and without load. This is done with the aim that we can know the character of the three-phases asynchronous slip ring motor practically not only theoretically. In this experiment used three-phases asynchronous slip ring motor Feedback Type 243.

The variables observed in this test are isolation resistance and coil, then carried unloaded test by adjusting motor rotation with resistance in range $25 \Omega$, $20 \Omega, 15 \Omega, 10 \Omega, 5 \Omega, 0 \Omega$. From this result obtained in the form of line voltage, phase voltage, frequency, power factor, power, line current, phase current, motor rotation, motor torque, and anchor coil resistance. Then for loaded testing is done by adjusting motor rotation with resistance in the range $25 \Omega, 20 \Omega, 15 \Omega, 10 \Omega, 5 \Omega, 0 \Omega$. After that we have been set the voltage percent as variable load generator. Starting from voltage $20 \%, 40 \%$, $60 \%, 80 \%, 100 \%$. From this, researchers get the result of motor rotation, motor torque, power input, power output, efficiency, current, power factor, voltage, and frequency.

After completion of the experiment, the result must be processed with several formulas, including power, torque, power output, efficiency, and slip loss.

$>$ Power calculation:

$\mathrm{P}=\sqrt{3} \times \mathrm{V} \times \mathrm{I} \times \operatorname{Cos} \phi$

Torque calculation:

$\mathrm{T}=\frac{P}{\omega}=\frac{P}{2 \pi(r p s)}$

Power output calculation:

$\mathrm{P}_{\text {out }}=(2 \times \pi \times \mathrm{N} \times \mathrm{T}) / 60$

$>$ Calculation of efficiency:

$\eta=\frac{P_{\text {out }}}{P_{\text {in }}}$

$>$ Calculation Slip loss:

Slip loss $=\mathrm{P} \times\left(\mathrm{S}_{1}-\mathrm{S}_{0}\right)$

\section{RESULTS AND DISCUSSION}

In the analysis and discussion stage about performance analysis of three-phases asynchronous slip ring motor by Feedback Type 243, in the first, the researchers learning the module which issued by manufacturer of feedback there is explanation about component used for practicum three-phases asynchronous slip ring motor Feedback Type 243 as well as procedures for conducting practicum activities for data retrieval used for analysis in this discussion. Data taken at the time of the practicum is Current Line Voltage $\left(\mathrm{V}_{\text {line }}\right)$, Voltage phase $\left(\mathrm{V}_{\text {phase }}\right)$, Frequency, Power factor $(\operatorname{Cos} \Phi)$, Power, Line current ( $\left.\mathrm{I}_{\text {line }}\right)$, Current phase ( $\left.\mathrm{I}_{\text {phase }}\right)$, Resistance coil anchor, Motor torque, Input Power, Output Power, Efficiency, Insulation Resistance. In this research used two methods 
that is with loaded and unloaded motor conditions, for loaded motor generator used as the load. It also measures the insulation resistance by using insulation tester to determine whether the motor condition is still in good condition or not before use.

After getting all the data that if needed by practices then the calculation have been done to know the performance of three-phases asynchronous slip ring motor that is start from calculation of input power and motor output power and also calculation of torque generated by motor, also done calculation of motor efficiency for knowing how the current motor condition is still in good condition or less good after long time not used and whether impact on its performance. It also measures the insulation resistance by using insulation tester to determine whether the motor condition is still in good condition or not before use. In this chapter also performed graph analysis to determine the relation of parameters-parameters that have been calculated to draw conclusions at the end of this research.

\section{1) Data Processing}

The experimental research of three-phases asynchronous slip ring motors was conducted on March 6, 2017 to finish in Marine Electrical and Automation Laboratory, Department of Marine Engineering, Institut Teknologi Sepuluh Nopember Surabaya to obtain the data in Table 1 - Table 4.

TABLE 1.

ISOLATION RESISTANCE VALUE Standard Value (I.E.E.E.) Year Manufacture of motor $>1970$

\begin{tabular}{lcl} 
Isolation Resistance Value & $\begin{array}{c}\text { Standard Value } \\
\text { (I.E.E.E.) } \\
\text { Year Manufacture of } \\
\text { motor }>1970\end{array}$ & \multicolumn{1}{c}{ Information } \\
\hline $\mathrm{K}-\mathrm{K}$ & $\mathrm{IR} 1 \mathrm{~min}>100 \mathrm{M} \Omega$ & $\begin{array}{l}\text { According standardization I.E.E.E, } \\
\text { insulation resistance value owned three- } \\
\text { phases Asynchronous Slip ring Motor is still } \\
\text { good because of }>100 \mathrm{M} \Omega\end{array}$ \\
\hline Bearing Condition: Good & $\begin{array}{l}\text { For bearing condition of three-phases Asynchronous Slip ring Motor is in } \\
\text { good condition, because there is no sound of friction from bearing on this } \\
\text { motor, or sound smooth. }\end{array}$ \\
\hline
\end{tabular}

Discussion:

In three-phases asynchronous slip ring motor anchor coils on the stator (U1-U2 $=34.5 \Omega, \mathrm{V} 1-\mathrm{V} 2=34.5$ $\Omega, \mathrm{W} 1-\mathrm{W} 2=34.5 \Omega$ ). The three-phases asynchronous slip ring motor also has an isolation resistance $(\mathrm{K}-\mathrm{K}=500 \mathrm{M} \Omega)$.

Bearing condition of three-phases asynchronous slip ring motor turning phase is in good condition, because there is no friction noise from bearing on this motor so that at the time of this asynchronous motor rotates no occurrence or incidence of vibration on motor because spin on bearing smooth so rotation of motor can maximize.

a. Unloaded Experiment

Motor with resistance $25 \Omega-21 \Omega$

TABLE 2.

MOTOR WITH RESISTANCE $25 \Omega-21 \Omega$

\begin{tabular}{|c|c|c|c|c|c|c|}
\hline \multirow{2}{*}{$\begin{array}{c}\text { Resistance } \\
(\Omega)\end{array}$} & \multirow{2}{*}{$\begin{array}{c}\text { Freq } \\
(\mathrm{Hz})\end{array}$} & \multirow{2}{*}{$\begin{array}{l}\text { Power } \\
\text { (Watt) }\end{array}$} & \multirow{2}{*}{$\begin{array}{c}\text { V line } \\
(\mathrm{V})\end{array}$} & \multicolumn{3}{|c|}{$V$ phase $(V)$} \\
\hline & & & & $\mathbf{R}$ & $\mathbf{S}$ & $\mathbf{T}$ \\
\hline 25 & 50 & 58 & 383 & 382 & 385 & 383 \\
\hline 24 & 50 & 58 & 383 & 382 & 384 & 383 \\
\hline 23 & 50 & 58 & 383 & 386 & 388 & 387 \\
\hline 22 & 50 & 58 & 382 & 380 & 382 & 382 \\
\hline 21 & 50 & 58 & 383 & 384 & 386 & 386 \\
\hline \multirow{2}{*}{$\begin{array}{c}\text { I line } \\
\text { (A) }\end{array}$} & \multicolumn{3}{|c|}{ I phase (A) } & \multirow{2}{*}{$\begin{array}{c}\text { Rotation } \\
\text { (Rpm) }\end{array}$} & \multirow{2}{*}{$\operatorname{Cos} \phi$} & \multirow{2}{*}{$\begin{array}{c}\text { Torque } \\
\text { (Nm) }\end{array}$} \\
\hline & $\mathbf{R}$ & $\mathbf{S}$ & $\mathbf{T}$ & & & \\
\hline 0,258 & 0,302 & 0,302 & 0,302 & 2509 & 0,34 & 0,220861 \\
\hline 0,263 & 0,301 & 0,305 & 0,296 & 2515 & 0,33 & 0,220334 \\
\hline 0,271 & 0,301 & 0,305 & 0,3 & 2540 & 0,33 & 0,218165 \\
\hline 0,278 & 0,301 & 0,304 & 0,292 & 2558 & 0,32 & 0,21663 \\
\hline 0,285 & 0,304 & 0,308 & 0,296 & 2608 & 0,32 & 0,212477 \\
\hline
\end{tabular}


International Journal of Marine Engineering Innovation and Research, Vol. 2(1), Dec. 2017. 01-07 (pISSN: 2541-5972, eISSN: 2548-1479)

b. Loaded Experiment

Motor with resistance $25 \Omega$

TABLE 3.

MOTOR WITH RESISTANCE $25 \Omega$

\begin{tabular}{|c|c|c|c|}
\hline \% load & P (Watt) & $\operatorname{Cos} \phi$ & $\begin{array}{c}\text { Rotation } \\
\text { (Rpm) }\end{array}$ \\
\hline 20 & 22,43 & 0,51 & 1662 \\
\hline 40 & 47,37 & 0,51 & 1519 \\
\hline 60 & 70,00 & 0,51 & 1060 \\
\hline 80 & 90,00 & 0,51 & 791 \\
\hline 100 & 109,31 & 0,51 & 502 \\
\hline$\underset{\text { (Watt) }}{P \text { in }}$ & $\begin{array}{c}\text { Torque } \\
\text { (Nm) }\end{array}$ & $\begin{array}{c}\text { Efficiency } \\
\%\end{array}$ & $\begin{array}{c}\text { P out } \\
\text { (Watt) }\end{array}$ \\
\hline 102,0 & 0,13 & 0,22 & 22,43 \\
\hline 103,0 & 0,55 & 0,55 & 87,44 \\
\hline 110,0 & 1,43 & 0,75 & 90,00 \\
\hline 120,6 & 1,79 & 0,83 & 100,00 \\
\hline 127,9 & 2,08 & 0,85 & 109,31 \\
\hline
\end{tabular}

- $\quad 25 \Omega$ On Display

TABLE 4.

MOTOR WITH RESISTANCE $25 \Omega$

\begin{tabular}{cccccc}
\hline$\%$ Fload & $\begin{array}{c}\text { Freq } \\
(\mathbf{H z})\end{array}$ & $\begin{array}{c}\text { Power } \\
\text { (Watt) }\end{array}$ & $\begin{array}{c}\text { V line } \\
(\mathbf{V})\end{array}$ & $\begin{array}{c}\text { I line } \\
(\mathbf{A})\end{array}$ & Cos $\boldsymbol{\phi}$ \\
\hline 0 & 50 & 112 & 380 & 0,351 & 0,51 \\
\hline 20 & 50 & 116 & 382 & 0,352 & 0,51 \\
\hline 40 & 50 & 122 & 385 & 0,38 & 0,51 \\
\hline 60 & 50 & 124 & 388 & 0,391 & 0,51 \\
\hline 80 & 50 & 126 & 390 & 0,394 & 0,51 \\
\hline 100 & 50 & 127 & 392 & 0,41 & 0,51 \\
\hline
\end{tabular}

2) Graphical Analysis

Calculation of several factors that influence from this research about the analysis of three-phases asynchronous slip ring motor. Then the next step is to graph the parameters that have been calculated to determine the relationship between each parameter. In analyzing the graph have been be divided into two types namely the motor without load and motor loaded because to know the character of the motor we must analyze changes in motor conditions when without load and loaded with a predetermined variable.
Motor Unloaded

In this sub-chapter have been be made graph of the relationship between several parameters when the motor is without load. After the graph have been be analyzed the relationship between these parameters to learn the character of the motor. The graphs are based on the calculated data of motor torque and motor rotation.

- Relation between Torque and speed on resistance $25 \Omega$ $-21 \Omega$.

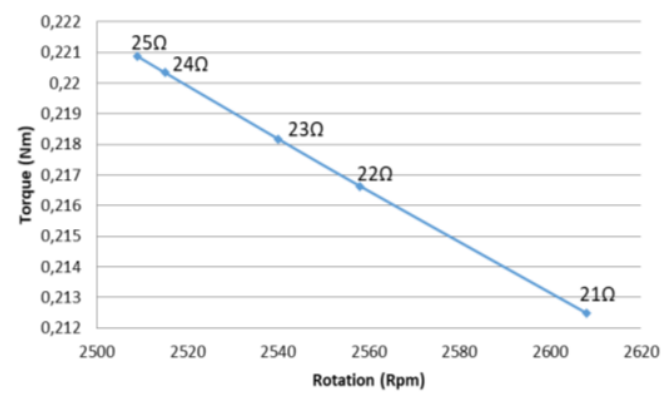

Figure. 5. Torque vs Speed 
In Figure 5 shows that the value of the rotation have been continue to rise each lowered its resistance, starting from the resistance of $25 \Omega$ until it is lowered to a resistance of $21 \Omega$. As for the value of torque here, we can see the value of torque decreases every time we lower the resistance. Both are derived from the resistance of $25 \Omega-21 \Omega$, This corresponds to the torque formula $\mathrm{T}=\mathrm{P} /(2 \pi(\mathrm{rps}))$ where if the value of the rotation is raised, for the value of the torque have been decrease.
Motor Loaded

After doing the experiment then the graph is made between motor speed when some variation of resistance is used with motor torque and also graph between efficiency with load. The graph is described in the graph as follows:

- Relation between motor speed and motor torque on the resistance $25 \Omega$.

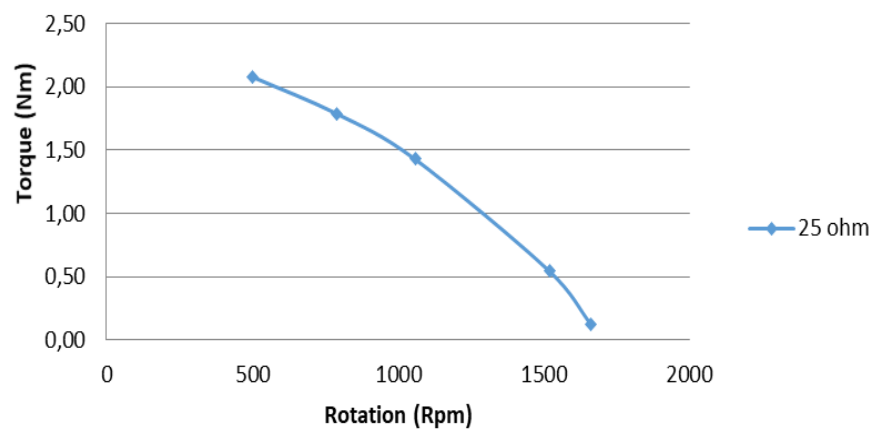

Figure. 6. Relation between motor speed and motor torque on the resistance $25 \Omega$

Figure 6 shows the relation between motor speed and motor torque on the $25 \Omega$ resistance. From the Figure 6 shows that the greater the motor speed the motor torque have been smaller. So it can be said the relation between motor torque with speed inversely proportional. This corresponds to the torque formula $\mathrm{T}=\mathrm{P} /(2 \times \pi \times \mathrm{rps})$ where if the value of the rotation is increased, for the value of the torque have been decrease. Figure 7 is actually the same as the characteristic chart of torque vs speed SRM (Slip Ring Motor) which is used as a reference.

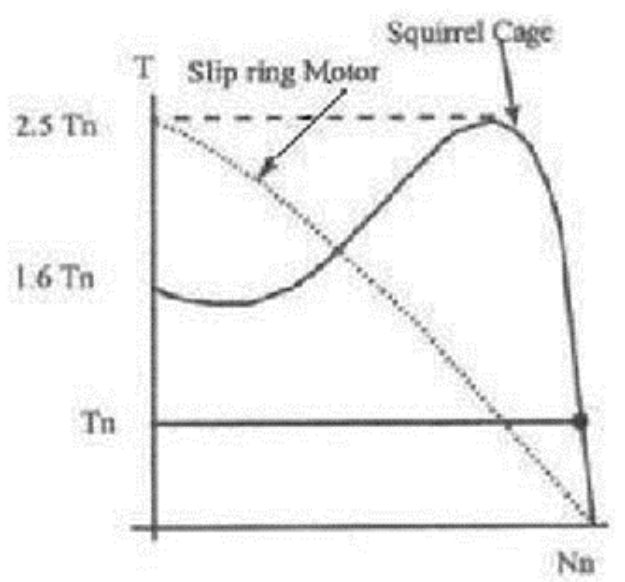

Figure. 7. Torque vs speed SRM and SCM

- The relation between motor efficiency and motor load at resistance $25 \Omega$

From the Figure 8 shows efficiency is calculated by comparing the output power with input power. The Figure 8 illustrates the relationship between efficiency to load for some voltage variations. From the Figure 8 shows that the greater the load, the efficiency tends to rise and actually the same as the efficiency of asynchronous slip ring motor that is used as a reference. 


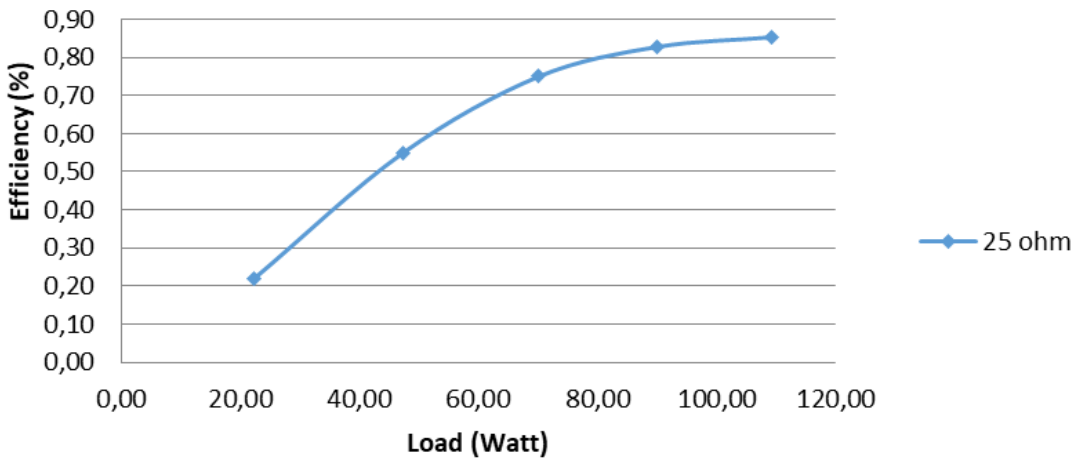

Figure. 8. The relation between efficiency and load at resistance $25 \Omega$

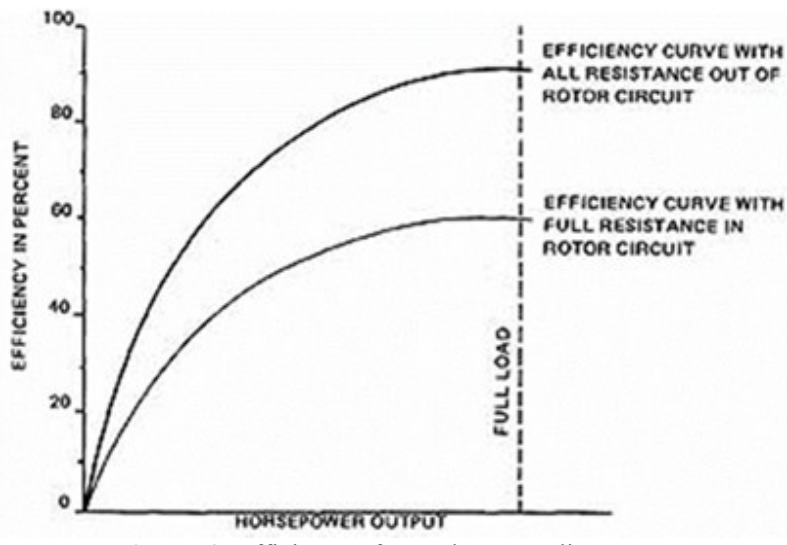

Figure. 9. Efficiency of asynchronous slip motors

The three-phasess asynchronous slip ring motor is suitable for applications with load changes and sudden speed changes on the motor. Examples of such applications are elevators, cranes, extractors, ball and sag mills, cranes, hoists, pumps, fans and blowers, chippers, conveyors.

\section{CONCLUSION}

After analysis of three-phases asynchronous slip ring motor performance Feedback Type 243 then the researchers have these following conclusions:

In the experimental results the maximum torque resistance at $25 \Omega$ is $2,08 \mathrm{Nm}$ obtained motor rotation 502 $\mathrm{rpm}$, the resistance $20 \Omega$ the maximum torque is $1,53 \mathrm{Nm}$ obtained motor rotation $673 \mathrm{rpm}$, the resistance $15 \Omega$ maximum torque is $1,23 \mathrm{Nm}$ obtained motor rotation 838 $\mathrm{rpm}$, the resistance $10 \Omega$ maximum torque is $0,98 \mathrm{Nm}$ obtained motor rotation $1035 \mathrm{rpm}$, the resistance $5 \Omega$ maximum torque is $0,8 \mathrm{Nm}$ obtained $1243 \mathrm{rpm}$ motor rotation. the resistance $0 \Omega$ maximum torque is $0,67 \mathrm{Nm}$ obtained $1462 \mathrm{rpm}$ motor rotation.

The maximum load value obtained on the resistance $25 \Omega$ is 109,31 watt with an efficiency of $85 \%$, at $20 \Omega$ the maximum load is 107,86 watts with an efficiency of $81 \%$, at $15 \Omega$ the maximum load is 107,58 watts with an efficiency of $82 \%$, at a resistance of $10 \Omega$ the maximum load is 106,5 watt with an efficiency of $87 \%$, at $5 \Omega$ the maximum load is 104,62 watt with an efficiency of $93 \%$, at $0 \Omega$ the maximum load is 103,29 watts with an efficiency of $95 \%$ It can be concluded that the greater the load, the efficiency tends to rise in the experiment of the relationship between the efficiency of motor loading.

\section{REFERENCES}

[1] B.L Theraja, "A Texbook of Electrical Technology", S. Chand, New Delhi, 2005.

[2] Kirtley, J. dan Ghai, N., Electric Motor Handbook, Mc-GrawHill, 2004.

[3] Sarwito, Sardono. 2016. Automatic Stacking Crane Prototype using Microcontroller Arduino Mega 2560. International Journal of Marine Enginnering and Innovation Research.

[4] Sarwito, Sardono. 2016. Design of Automatic Transfer Switch ACOS with Human Machine Interface Monitoring System in Shipboard Application. International Journal of Marine Enginnering and Innovation Research.

[5] Sarwito, Sardono. 2017. Study of Calculation of Degaussing System for Reducting Magnetic Field from Submersible Vehicle. International Journal of Marine Enginnering and Innovation Research.

[6] Sarwito, Sardono. 2017. Analysis of Electric Propulsion Performance on Submersible with Motor DC, Supply Power $10260 \mathrm{AH}$ at Voltage 115VDC. International Journal of Marine Enginnering and Innovation Research.

[7] FEEDBACK Torque / Speed Characteristics of an Asynchronous Motor - Slip Ring, Feedback Powerframes Laboratory Note number 243 : Feedback Instruments Ltd, Park Road, Crowborough, E. Sussex, TN6 2QR, UK.

[8] FEEDBACK Machines Loading System ETL 174-3, ETL174N Swinging Field Dynamometer : Feedback Instruments Ltd, Park Road, Crowborough, E. Sussex, TN6 2QR, UK.

[9] FEEDBACK Starting a Three Phase Asynchronous Motor with a Resistance Starter, Feedback Powerframes Laboratory Note number 140 : Feedback Instruments Ltd, Park Road, Crowborough, E. Sussex, TN6 2QR, UK.

[10] FEEDBACK Effect of Rotor Resistance on the Starting Torque of an Asynchronous Motor, Feedback Powerframes Laboratory Note number 142 : Feedback Instruments Ltd, Park Road, Crowborough, E. Sussex, TN6 2QR, UK.

[11] FEEDBACK Speed Control of a Three Phase Asynchronous Motor by Means of Rotor Resistance, Feedback Powerframes Laboratory Note number 141 : Feedback Instruments Ltd, Park Road, Crowborough, E. Sussex, TN6 2QR, UK. 